\author{
Евангельский пласт в архитектонике \\ рассказа Достоевского «Скверный анекдот» \\ Памяти Карена Степаняна
}

B.N. Tikhomirov

\title{
The Evangelical Stratum in the Architectonics of Dostoevsky's Short Story “A Nasty Story”
}

In memory of Karen Stepanyan

Об авторе: Борис Николаевич Тихомиров, доктор филологических наук, заместитель директора по научной работе Литературно-мемориального музея $Ф$. М. Достоевского, Санкт-Петербург.

E-mail: btikhomirov@rambler.ru

Аннотация: Рассказ Достоевского «Скверный анекдот» рассматривается как рубежное произведение в эволюции творческой системы Достоевского. В центре внимания автора система библейских интертекстов в художественной структуре рассказа, играющая исключительную роль в организации художественного целого произведения и воплощении авторской позиции. В фабульной ситуации посещения либеральным генералом Пралинским свадебного пира своего подчиненного Пселдонимова Достоевский травестирует евангельский эпизод брака в Кане Галилейской, а динамический сюжет строит как фарсовую реализацию евангельской параболы Христа о новом вине и новых/ старых мехах. Герой рассказа, претендующий стать апостолом «гуманности», которая, по его убеждению, «всё спасет» и приведет к «обновлению вещей», через систему новозаветных интертекстуальных отсылок пародийно соот-

Доклад, прочитанный 10 ноября 2018 г. на XLIII Международной конференции «Достоевский и мировая культура» в Литературно-мемориальной музее Ф. М. Достоевского в Петербурге. 
носится то с апостолами, то с Иоанном Крестителем, то с самим Спасителем, в результате чего обнаруживается (по контрасту), что для роли, на которую он претендует, у генерала Пралинского совершенно негодные средства и что решить те задачи, за которые он берется, можно только на христианских, а не на либеральных путях.

Ключевые слова: Достоевский, «Скверный анекдот», поэтика, архитектоника, интертекстуальность, аллюзия, Новый Завет.

Для цитирования: Тихомиров Б. Н. Евангельский пласт в архитектонике рассказа Достоевского «Скверный анекдот» // Достоевский и мировая культуpa. 2018. No 4. С. 65-77. DOI 10.22455/2619-0311-2018-4-65-77

About the author: Boris N. Tikhomirov, Doctor of Philological Sciences, Deputy Research Director of F.M. Dostoevsky Literary-Memorial Museum, St. Petersburg.

E-mail: btikhomirov@rambler.ru

Abstract: Dostoevsky's “A Nasty Story” is examined as a landmark piece of work in the evolution of Dostoevsky's creative system. The author focuses his attention on the system of Biblical intertexts in the artistic structure of the story, a system that plays the peculiar role both in organizing the creative cohesion of the short story and in embodying Dostoevsky's position. In the anecdotal situation of the liberalminded general Pralinsky's visit to his subordinate Pseldonimov's marriage feast, Dostoevsky travesties the Evangelical episode of the marriage in Cana of Galilee, and organizes the plot as a farcical realization of Christ's parable about new wine and old/new wineskins. The narrator pretending to become an apostle of a "humanism" that, in his mind, "will save everything" and lead to the "renewal of things", by means of a system of New Testament intertextual references is correlated parodically to Apostles, to John the Baptist, and even to the Savior. As a result we can see, by contrast, that general Pralinsky's means are pitifully unfit for the role he is claiming, and that the tasks he is setting to can be completed only by Christian (and not liberal) ways.

Key words: Dostoevsky, “A Nasty Story”, poetics, architectonics, intertextuality, allusions, New Testament

For citation: Tikhomirov B. N. The Evangelical Stratum in the Architectonics of Dostoevsky's Short Story “A Nasty Story” // Dostoevsky and World Culture. 2018. No 4. Pp. 65-77. DOI 10.22455/2619-0311-2018-4-65-77 
Настоящий доклад является фрагментом большой работы ${ }^{1}$, в которой я рассматриваю рассказ 1862 года «Скверный анекдот» как глубоко новаторское, даже экспериментальное произведение, разрабатывающее новые принципы поэтики зрелого Достоевского и в силу этого знаменующее важный рубеж в эволюции творческой системы писателя.

Новозаветная интертекстуальность в «Скверном анекдоте» уже была затронута в ряде современных исследований, появившихся в середине 1990-х гг. (далее я их упомяну по ходу изложения). И однако этот важнейший элемент поэтики рассказа настолько мало разработан, что, например, в 5-м томе петрозаводских Канонических текстов ключевая и открыто лежащая на поверхности евангельская реминисценция «нового вина и новых мехов» даже не упомянута в комментариях (см.: [Достоевский 1995-2016: V, 716]) Что же касается новейшего академического собрания сочинений (5-й том 2-го издания), то хотя в реальном комментарии объем выявленных евангельских интертекстов и увеличен по сравнению с 1-м изданием в три с половиной раза, однако в статейных примечаниях лишь пробросом, в одной фразе отмечена «связь произведения Достоевского с библейской <...> и евангельской традициями» [Достоевский 2013-2016: V, 407], а весьма существенная цитата из работы Н. В. Живолуповой, конкретизирующая этот тезис, спущена в подстрочное примечание, никак не прокомментирована и не осмыслена [Там же].

В то же время новозаветные интертексты образуют глубинную семантическую основу рассказа, и Р.Г. Лейбов с полным правом отмечает, что в «Скверном анекдоте», «как обычно, Достоевский шел путем выявления в анекдоте глубинного смысла. Как обычно, инструментом этого выявления было соотнесение с Писанием» [Лейбов: 171]. Сказанное исследователем совершенно справедливо, но с той необходимой оговоркой, что «обычным» это станет для позднейшего творчества Достоевского, особенно для романов «великого пятикнижия». Однако до «Скверного анекдота» такой густоты библейской интертекстуальности и ее повышенной значимости в организации художественного целого мы не встречаем ни в одном произведении писателя. И именно это наблюдение позволило мне выше охарактеризовать рассказ как рубежное произведение в эволюции творческой системы Достоевского.

1 Публикуется в изд.: [Достоевский 2018] (в печати). 
В упомянутой большой работе фабульную ситуацию «Скверного анекдота» - нисхождение штатского генерала Пралинского, явившегося на брачный пир одного из самых ничтожных своих подчиненных, чиновника XIV разряда Пселдонимова, я первоначально вполне фигурально обозначил как «генеральский кенозис». Однако по мере аналитического рассмотрения рассказа эта условная, риторическая формула начала наполняться все более определенным, имеющим прямое отношение к глубинной проблематике произведения содержанием. Остановлюсь на этом чуть подробнее.

В контексте типологии героев Достоевского генерал Пралинский представляет собою позднюю и весьма своеобычную вариацию типа мечтателя. Он, по авторскому определению, «поэт в душе» [Достоевский 1972-1990: V, 7]². И перед тем как войти в дом Пселдонимова Иван Ильич в воображении мечтательно «моделирует» идеальную картину своего «явления» на свадьбе подчиненного. Всё, что должно произойти, рисуется в его фантазии весьма подробно, и всё исходит из сознания Пралинским своей личной исключительности. «Разумеется, сначала он (Пселдонимов - Б.Т.) испугался бы, онемел бы от замешательства, рассуждает герой. - Я помешал бы ему, я расстроил бы, может быть, всё... Да, так и было бы, если б вошел всякий другой генерал, но не я... В том-то и дело, что всякий, да только не я» [Достоевский 19721990: V, 13].

Именно в свете мечтаний Пралинского картина его явления в доме подчиненного как раз и предстает как «генеральский кенозис»³. В прожекте героя генерал, в полной мере оставаясь генералом, всемерно сохраняя сознание, «что они и я - это разница-с. Земля и небо» [Достоевский 1972-1990: V, 14], нисходит до чиновничьей мелюзги и устанавливает отношения «на равной с ними ноге» [Там же]. По убеждению генерала-мечтателя, уже сам по себе этот «кенотический акт» должен произвести на Пселдонимова и всех присутствующих на свадьбе чудотворное действие. «Да ведь я униженного нравственно подыму, я самому себе его возвращу...»; «мой поступок воскресит в них всё благородство» [Там же], - мечтательно восклицает он. Генеральство

2 В написанном через шесть лет после «Скверного анекдота» романе «Идиот» этими же словами, «поэт в душе», будет охарактеризован вдохновенный враль и фантазер генерал Иволгин (см.: [Достоевский 1972-1990: VIII, 109]).

3 Этим термином богословы обозначают жертвенное самоуничижение Иисуса Христа, Бога вочеловечившегося, «Царя небесного», который «в рабском виде» совершил свой земной путь, претерпев в конце осмеяние и поругание и приняв крестную смерть на Голгофе. 
Пралинского в его воображении как бы осеняет Пселдонимова и всех вокруг благодатью. И именно своим генеральством, снизошедшим до коллежского регистратора на десяти рублях жалования, намеревается он совершенно парадоксальным образом воскресить собственно человеческое достоинство своего подчиненного, пребывающего на самом низу иерархической лестницы.

В воображении героя событие это приобретает значение «священнейшего анекдота» [Там же], который в роду Пселдонимовых не изгладится из памяти и будет передаваться из поколения в поколение.

Эта генеральская фантазия весьма забавна. Но необходимо прояснить один пункт. «Мы все кричим о гуманности, но героизма, подвига мы сделать не в состоянии» [Достоевский 1972-1990: V, 13], обращается Иван Ильич на пороге дома Пселдонимова с мысленным упреком к воображаемым оппонентам. Почему этот «кенотический акт», совершаемый ради «гуманности», мыслится Пралинским как «подвиг» и «героизм»? Он сам отвечает на этот вопрос так: «Какого героизма? Такого. Рассудите-ка: при теперешних отношениях всех членов общества мне, мне войти в первом часу ночи на свадьбу своего подчиненного, регистратора, на десяти рублях, да ведь это замешательство, это - коловращенье идей, последний день Помпеи, сумбур!» [Там же].

«При теперешних отношениях всех членов общества»: Иван Ильич остро сознает, что такой эксцентрический поступок (он сам назовет его далее «диким») идет вразрез с существующей системой иерархических отношений, ее поведенческими нормами и господствующими идеями; что в общественном мнении это должно восприниматься как «сумбур» и даже потрясение основ («последний день Помпеи»). Он сам в себе, в своем генеральском сознании чувствует давление общепринятых представлений, их сопротивление своему фантастическому намерению. Но, как сказано в рассказе, «звезда увлекала его» [Достоевский 19721990: V, 15]. И «подвигом», «героизмом» он именует преодоление власти над своим сознанием господствующих идей, общественных норм и стереотипов. Именно в этом смысле необходимо понимать его восклицание: «...а я вы-дер-жу!» [Достоевский 1972-1990: V, 13].

В романе «Бесы» Николай Ставрогин изрекает афоризм: «Нужно быть действительно великим человеком, чтобы суметь устоять даже против здравого смысла». А затем прибавляет: «Ну, равно и дураком» [Достоевский 1972-1990: Х, 209]. Смысл этого последнего корректива в том, что для противостояния здравому смыслу достаточно сознания 
своей исключительности, веры в то, что ты «великий человек». И именно таково сознание Ивана Ильича Пралинского, провоцирующее его (при посредстве также шести бокалов шампанского) на его экстравагантный поступок.

Вот как воображает генерал результат своего явления на свадьбе Пселдонимова: «Я обращу последний день Помпеи в сладчайший день для моего подчиненного, и поступок дикий - в нормальный, патриархальный, высокий и нравственный <...> Да ведь повтори я это раз пять, али десять, али что-нибудь в этом же роде, так повсеместную популярность приобрету... У всех в сердцах буду напечатлен, и ведь черт один знает, что из этого потом может выйти, из популярностито!..» [Достоевский 1972-1990: V, 13, 14-15]. Генералу Пралинскому мечтается именно «коловращенье идей», то есть радикальная перемена общественного мнения. «Генеральский кенозис», увенчанный нравственным воскрешением одного из «малых сих», воображается героем как чудотворный не только в рамках отдельно взятого брачного пира в доме Пселдонимова, но и в отношении всего общества. То, что прежде представлялось «диким», воспринималось как потрясение основ, обращается во всеобем восприятии в поступок «нормальный, патриархальный, высокий и нравственный». Деяние Ивана Ильича Пралинского как бы дает начаток новой нормы и новой нравственности. Говоря его собственными словами: «Вот тут-то и сок!».

Представляется, что так высоко не заносился еще никто из героевмечтателей Достоевского. Но тут также становится ясным, что явившийся с такими мечтами на свадьбу своего подчиненного генерал самозванещ. И это очень скоро обнаруживается в дальнейшем действии.

Впрочем, то, что перед нами не просто подвыпивший восторженный генерал-недотепа, совершающий опрометчивый, нелепый поступок, но именно самозванец, возможно, и не вполне очевидно. Поэтому нелишне отметить некоторые детали. В Прологе, открывающем рассказ, генераллиберал Иван Ильич Пралинский произносит спич, в котором выступает с проповедью гуманности. В «силлогизмах», которые он разворачивает перед своими оппонентами, генералами-консерваторами Никифоровым и Шипуленко, она с очевидностью профанируется и предстает откровенно пародийно, даже карикатурно. Но рядом с этой пародийной проекцией идеи «гуманности», в какой-то трудноуяснимой связи с нею, в речах Пралинского возникает иная, вполне серьезная. Уже наедине с самим собой, договаривая то, что осталось им невысказанным в споре с оппонентами, Иван Ильич высказывается существенно иначе: «Главное 
то, что я убежден, душою убежден. Гуманность... человеколюбие. Возвратить человека самому себе... возродить его человеческое достоинство и тогда... с готовым матерьялом приступайте к делу. Кажется ясно! Да-с!» [Достоевский 1972-1990: V, 11]. Здесь с проблемы «гуманности» сорвана карикатурная оболочка, и формулируется нешуточная идея необходимости преображения человека в его сегодняшнем состоянии, преображения и возрождения человека, без чего и все предстоящие реформы будут тщетны. Больше того, сверхзадача, которая указана в этих словах, далеко выходит за рамки сиюминутного вопроса об одном лишь проведении конкретных общественных реформ, колоссально перерастает эти рамки, переносит нас из области истории в сферу онтологии человеческого бытия. И мерещится, что здесь звучит уже не голос героя - генерала Пралинского, «парлёра», любящего «принимать парламентские позы» [Достоевский 1972-1990: V, 7], но голос автора рассказа, самого Достоевского.

Выше уже было отмечено, что именно подобное преображение Пселдонимова и гостей на его свадьбе как следствие совершаемого им «кенотического акта» и мерещилось генералу Пралинскому, когда он переступал порог дома своего подчиненного. И тут читатель прикасается к глубинному замыслу Достоевского. Но вполне очевидно это раскрывается при специальном внимании к роли библейской интертекстуальности в рассказе, которая и оказывается важнейшим средством выражения авторской позиции.

Регулярные отсылки к Священному Писанию, преимущественно к Новому Завету, содержащиеся как в речах персонажей, так и в авторском изложении, буквально прослаивают «Скверный анекдот» и задают специфическую оптику восприятия, при которой анекдотическое происшествие в Петербурге начала 1860-х гг. предстает на фоне и, как отмечено Р. Г. Лейбовым, в соотнесении с евангельским повествованием.

Ключевой для уяснения принципов художественной организации рассказа является новозаветная парабола о «новом вине» и новых и старых «мехах», которую в ответ на осаживающую реплику генерала Никифорова: «Не выдержим» - вспоминает генерал Пралинский. «Это вы уж не насчет ли нового вина и новых мехов? - не без иронии возразил Иван Ильич. - Ну, нет-с; за себя-то уж я отвечаю» [Достоевский 1972-1990: V, 9].

В Евангелии, приступая к проповеди Своего учения, которое Он основывает не на иудейском законе, а на Самом Себе как новом абсолюте, Иисус Христос, обращаясь к порицающим Его книжникам 
и фарисеям, иносказательно утверждает, что Его Слово не может быть вмещено ветхозаветным сознанием и адресовано апостолам - простецам из народа, свободным от догматической книжной премудрости. «Никто к ветхой одежде не приставляет заплаты из небеленой ткани: иначе вновь пришитое отдерет от старого, и дыра будет еще хуже, поучает Он. - Никто не вливает вина молодого в мехи ветхие: иначе молодое вино прорвет мехи, и вино вытечет, и мехи пропадут; но вино молодое надобно вливать в мехи новые» (Мк. 2: 21-22). «Кусок новой ткани и новое вино, - поясняет смысл этих парабол один из учителей Церкви св. Иероним Стридонский, - должны быть понимаемы в смысле заповедей Евангелия, которых не могут выносить иудеи, чтобы разрыв не сделался еще большим. Этого именно и хотели Галаты, то есть хотели смешивать с Евангелием заповеди Закона и вливать новое вино в мехи ветхие; но апостол говорит им: О, несмысленные Галаты! кто прельстил вас не покоряться истине? (Гал. 3: 1) Итак, слово Евангелия гораздо более должно быть влито в апостолов, чем в книжников и фарисеев, которые не могли сохранить чистоты заповедей Христовых» [Иероним Стридонский: 68].

Как же функционирует интертекстуальная отсылка к приведенному новозаветному тексту в «Скверном анекдоте»? Модная в либеральных кругах эпохи реформ начала 1860-х гг. идея «гуманности», переведенная на язык евангельской образности, предстает в реплике генералалиберала Пралинского как «новое вино». Генералы-консерваторы Никифоров и Шипуленко выступают с позиции «ветхих мехов»: пришить «заплату» гуманности к «ветхой одежде» старой чиновничьебюрократической системы они считают невозможным. Система «не выдержит»: «молодое вино прорвет мехи». Их же молодой оппонент генерал Пралинский заносчиво почитает себя «новыми мехами». И если применение им к ситуации пореформенной России начала 1860х гг. Христовой параболы о «молодом вине» и новых/старых «мехах» продолжить приведенным толкованием этой притчи св. Иеронимом Стридонским, то надо заключить, что Никифорову и Шипуленко, «людям паралича и косности» [Достоевский 1972-1990: V, 13], Пралинский оставляет роль «фарисеев и книжников» старой чиновничье-бюрократической системы, себя же мыслит, как минимум, «апостолом» новейшей либеральной идеи «гуманности».

Именно в плане этого уподобления в тексте «Скверного анекдота» возникает ряд как будто не мотивированных внешней фабулой рефлексов евангельского повествования, когда Пралинский то 
претендует стать, по словам Спасителя, обращенным к первоапостолам, «ловцом человеков» (Мф. 4: 19; ср. его слова: «...человек мой, человек уловлен, так сказать, сетями» - [Достоевский 1972-1990: V, 11], то сравнивается автором с волхвами, идущими на поклонение младенцу Христу («Звезда увлекала его» - [Достоевский 1972-1990: V, 15]; ср.: Мф. 2: 9-11)

В этом же плане функционирует и саркастическая травестия евангельского сюжета о пире Ирода, на котором Саломия потребовала подать ей на блюде голову Иоанна Крестителя (см.: Мф. 14: 10-11); ср. слова пьяного Пралинского: «...я пришел... я хотел, так сказать, крестить. <...> Он опустился на стул, как без памяти, положил обе руки на стол и склонил на них свою голову, прямо в тарелку с бламанже» [Достоевский 1972-1990: V, 34].

Однако евангельский текст отражается в рассказе Достоевского не только в серии отдельных, локальных сравнений и метафор, но просматривается и в основании общей фабульной ситуации рассказа - посещении генералом Пралинским бедной свадьбы коллежского регистратора Пселдонимова. Здесь вновь читатель сталкивается с саркастической перелицовкой новозаветного сюжета: «Иван Ильич Пралинский, не ведая того, пародирует евангельский эпизод брака в Кане Галилейской, кощунственно ставя себя на место Иисуса» [Лейбов: 163], - отмечает Р.Г. Лейбов.

В «Братьях Карамазовых» Достоевский в сонной грезе Алеши у гроба старца Зосимы изобразит брак в Кане Галилейской совершенно в ином ключе, создав собственную гениальную вариацию этого евангельского эпизода. Тем не менее в замечании о Спасителе, промелькнувшем в голове Алеши, «что не для одного лишь великого и страшного подвига Своего сошел Он тогда, но что доступно сердцу Его и простодушное немудрое веселие каких-нибудь темных, темных и нехитрых существ, ласково позвавших Его на убогий брак их» [Достоевский 1972-1990: $\mathrm{XIV}, 326]$, абсолютно точно сформулировано то, что вдохновляло генерала Пралинского, переступавшего порог дома Пселдонимова, что он хотел продемонстрировать всем собравшимся на свадьбе и благодаря чему мечтал снискать «всеобщую популярность». «Назавтра <...>, - гре-

4 По тонкому замечанию Р. Лейбова, усмотревшего в этих словах «наличие “вифлеемского" плана», «здесь обыгрывается распространенный в XIX веке каламбур: имеется в виду одновременно орденская звезда <...> и небесная звезда» [Лейбов: 172, примеч. 9]. Правда, исследователь пишет здесь «орденская звезда на груди у Пралинского», однако это не вполне точно: речь должна идти о новой звезде, которую герой мечтает получить за свой «подвиг». 
зилось ему, - все они уже знают, кто я такой. Душу мою знают, суть мою знают: “Он строг как начальник, но как человек - он ангел!” [Достоевский 1972-1990: V, 14]5.

Сквозной для рассказа мотив вина также связывает реальный и новозаветный планы рассказа. «И как недоставало вина, то Матерь Иисуса говорит Ему: вина нет у них» (Ин. 2: 3), - повествует евангелист, описывая брак в Кане Галилейской. В ответ на эти слова и совершает Спаситель Свое первое чудо - обращение воды в вино. Вина недостало и на свадьбе Пселдонимова, но - по той причине, что его вылакал начальник жениха, и, заняв денег у матери невесты, Пселдонимов посылал гонца еще за одной бутылкой. «Пралинский <...> не умножает количества вина и веселья на свадьбе, но, напротив, выпивает вино и в переносном смысле подвергает “крестной муке” жениха, заставляя его выпить чашу “желчи и оцта”» [Живолупова: 124], - отмечает Н.В. Живолупова. Так травестирует Достоевский в «Скверном анекдоте» хрестоматийный новозаветный текст, создавая тем самым контрастную подсветку изображаемым событиям современной действительности.

Но оригинальность, даже уникальность «Скверного анекдота» заключается в том, что не только общая фабульная ситуация, но и сам динамический сюжет рассказа имеет евангельские корни. Христова парабола о «молодом вине» и «старых мехах» использована Достоевским двояко. С одной стороны, как уже было отмечено, новозаветные метафоры этой притчи оказываются «языком», к которому прибегает Пралинский в дискуссии о «гуманности» с генералами-консерваторами, и благодаря этому существенно возрастает масштабность и значимость предмета их спора. Но, с другой стороны, сам сюжет «Скверного анекдота» фактически представляет собой фарсовую реализацию новозаветной метафоры, использованной в параболе Спасителя. Пралинский «не выдержал» не только в переносном смысле (оказался несостоятельным как деятель, вызванный новыми запросами времени), но и буквально: в результате многочисленных возлияний на свадьбе у Пселдонимова генерал заболел «чем-то вроде холерины»: «с Иваном Ильичом сделалось ужасное расстройство желудка <...> рвота и прочие неприятнейшие припадки не

5 См. также обращенные к Алеше (всё в той же сонной грезе героя) слова старца 3осимы: «Веселимся, пьем вино новое, вино радости новой, великой <...>. Не бойся Его [Христа]. Страшен величием перед нами, ужасен высотою Своею, но милостив бесконечно, нам из любви уподобился и веселится с нами...» [Достоевский 1972-1990: XIV, 327]. Парадоксально, но этот написанный через семнадцать лет после «Скверного анекдота» текст абсолютно точно представляет чаемое генералом Пралинским впечатление, которое он хотел бы произвести на всех присутствующих на свадьбе Пселдонимова. 
оставляли его ни на минуту», и мать Пселдонимова «всю ночь выносила через коридор из спальни необходимую посуду и вносила ее опять» [Достоевский 1972-1990: V, 39-40]; ср.: «...молодое вино прорвет мехи, и само вытечет, и мехи пропадут [расторгнетъ новое віно мъхи, и само изліется, и мъси погибнутъ, и.-сл.]» (Лк. 5: 37). Так, в результате приключившегося «скверного анекдота» «погиб» и генерал Пралинский - «погибла» и его репутация либерала и деятеля новой формации.

Наконец, необходимо указать иеще на один новозаветный интертекст, который открывает ряд библейских аллюзий в повествовании «Скверного анекдота», но обычно не привлекает к себе должного внимания, так как воспринимается в качестве обычного речевого клише. «...Я именно держусь и везде провожу идею, - проповедует Иван Ильич в Прологе, - что гуманность, и именно гуманность с подчиненными, от чиновника до писаря, от писаря до дворового слуги, от слуги до мужика, гуманность, говорю я, может послужить, так сказать, краеугольным камнем предстоящих реформ и вообще к обновлению вещей» [Достоевский 1972-1990: V, 8-9]. «Краеугольный камень» - фразеологизм библейского происхождения, обладающий как общеупотребительным, профанным, так и сакральным значением. Пралинским это выражение употреблено в качестве синонимической замены слов «основа», «основание». Не более того. Но в контексте «Скверного анекдота» в целом, в котором столь густо представлены библейские интертексты, определяющие глубинную семантическую структуру произведения, в этом выражении, особенно ретроспективно, при перечитывании рассказа, актуализируется и его сакральное значение.

Исключительно важно учесть, что в апостольских посланиях «краеугольным камнем» не однажды именуется «Сам Иисус Христос» (Еф. 2: 20). Так св. апостол Петр учит: «...сказано в Писании: “вот, Я полагаю в Сионе камень краеугольный, избранный, драгоценный: и верующий в Него не постыдится". Итак, Он [Христос] для вас, верующих, драгоценность, а для неверующих камень, который отвергли строители, но который сделался главою угла, камень претыкания и камень соблазна, о который они претыкаются...» (1 Пет. 2: 6-8).

Р.Г. Лейбов проницательно замечает, что «сатира Достоевского направлена не только против “старых мехов”, но и против мнимого “нового вина” - европейской гуманности» [Лейбов: 169]. Играпрофанным и сакральным значениями выражения «краеугольный камень» как раз и должна, по замыслу автора, обнаружить и заострить то обстоятельство, что «гуманность», которая, по упованию героя, «всё спасет» [Достоев- 
ский 1972-1990: V, 8], призванная способствовать «обновлению вещей» [Достоевский 1972-1990: V, 9], в декларациях либерального генерала Пралинского занимает то место, на которое для подлинно христианского сознания может быть поставлен только евангельский Христос. И это для Достоевского роковая подмена. Ибо для автора «Скверного анекдота» единственным истинным краеугольным камнем в деле преображения и возрождения человека является только Спаситель Нового Завета.

Гуманность же, которую столь велеречиво исповедует либеральный генерал Пралинский, - это, по позднейшей характеристике писателя, одна из «женевских идей», «то есть человеколюбие, то есть добродетель без Христа» - «идея всей теперешней цивилизации» [Достоевский 1972-1990: XVI, 35 и XIII; 173]. И герой «Скверного анекдота» оказывается в изображении Достоевского одним из тех горе-«строителей», которые отвергли истинный «краеугольный камень», сделавшийся для них, как и сказано апостолом, «камнем претыкания и камнем соблазна, о который они претыкаются...» ${ }^{6}$

Если теперь после сделанных наблюдений вернуться к метафоре «генеральский кенозис», неоднократно использованной выше для иронической оценки нисхождения героя рассказа к чиновничьей мелюзге и последствий, которых он ожидал от этого «кентического акта», то она уже не должна показаться столь произвольной. Нет, Иван Ильич Пралинский, конечно же, не ставит себя «кощунственно» на место Спасителя, как пишет Р. Лейбов. Он это делает, не отдавая себе отчета, как бессознательный самозванец. Показательно, что евангельские выражения, за единственным исключением ссылки на параболу о вине и мехах, он употребляет как обыкновенные речевые клише, абстрагируясь от их библейского происхождения (и показателем этого является повторяющееся «так сказать», которым он сопровождает каждый такой случай: «послужить, так сказать, краеугольным камнем», «человек уловлен, так сказать, сетями» и т. п.). Но он безотчетно использует евангельские формулы потому, что решить те задачи, за которые он берется, можно только на христианских, а не на либеральных путях. Это, напротив, отчетливо понимает автор рассказа, Достоевский, который уже сознательно через систему новозаветных интертекстуальных отсылок пародийно соотносит своего героя то с апостолами, то с Иоанном Крестителем, то с самим Христом, демонстрируя тем самым

6 Иронической аллюзией на евангельский мотив «претыкания ногою», возможно, является «претыкание» идущего на «подвиг» генерала Пралинского о блюдо с галантиром в темной прихожей Пселдонимова [Достоевский 1972-1990: V, 15]. 
по контрасту, что для роли, на которую он претендует, у либерального генерала Ивана Ильича Пралинского совершенно негодные средства.

\section{Список литературы}

1. Блаженного Евсевия Иеронима, пресвитера Стридонского четыре книги толкований на Евангелие от Матфея. М.: Учебно-информационный экуменический центр ап. Павла, 1998.272 c.

2. Достоевский Ф. М. Полн. собр. соч.: В 30 т. Л.: Наука, 1972-1990.

3. Достоевский Ф. М. Полн. собр. соч. и писем: В 35 т. СПб.: Наука, 2013-2016 (издание продолжается).

4. Достоевский Ф. М. Полн. собр. соч.: Канонические тексты. [Петрозаводск]: Изд. ПетрГУ, 1995-2016. Т. 1-9 доп., 11 (издание продолжается).

5. Достоевский Ф. М. Малая проза: В 2 т. / Сост., статья и комментарии Б. Н. Тихомирова. СПб.: Вита Нова, 2018. Т. 2 (в печати).

6. Живолупова Н. В. Трансформация мотива «подражания Христу» в произведениях Ф. М. Достоевского 60-х годов («Скверный анекдот», «Записки из подполья», «Крокодил») // Достоевский и современность: Материалы VIII Международных Старорусских чтений. Новгород, 1994. С. 121-130.

7. Лейбов Р. Заметки о «Скверном анекдоте» // Новое литературное обозрение. 1994. № 8. C. 158-173.

\section{References}

1. Blazhennogo Evseviia Ieronima, presvitera Stridonskogo chetyre knigi tolkovanii na Evangelie ot Matfeia [Of the Blessed Eusebius Hieronymus, Presbyter of Stridon, Four Books of Commentaries on Matthew]. Moscow, Uchebno-informatsionnyi ekumenicheskii tsentr ap. Pavla Publ., 1998. 272 p. (In Russ.)

2. Dostoevskii F. M. Poln. sobr. soch.: V 30 t. [Complete Works in 30 vols.]. Leningrad. Nauka Publ., 1972-1990. (In Russ.)

3. Dostoevskii F. M. Poln. sobr. soch. i pisem: V 35 t. [Complete Works in 35 vols.] St. Petersburg, Nauka Publ., 2013-2016. (In Russ.)

4. Dostoevskii F. M. Poln. sobr. soch.: Kanonicheskie teksty [Complete Works. Canonical Texts]. Petrozavodsk, Izd. PetrGU Publ., 1995-2016. T. 1-9 add., 11 (continuing edition)

5. Dostoevskii F. M. Malaia proza: V 2 t. [Small Proze: in 2 vols.], ed., introduction and comm. by B.N. Tikhomirov. St. Petersburg, Vita Nova Publ., 2018. Vol. 2 (in printing). (In Russ.)

6. Zhivolupova N. V. Transformatsiia motiva "podrazhaniia Khristu" v proizvedeniiakh F. M. Dostoevskogo 60-kh godov ("Skvernyi anekdot”, "Zapiski iz podpol'ia”, "Krokodil”) [Transformation of the Motive of "Imitating Christ" in F.M. Dostoevsky's Works of the 1860s ("A Nasty Story”, "Notes from the Underground”, "Crocodile”)]. Dostoevskii i sovremennost': Materialy VIII Mezhdunarodnykh Starorusskikh chtenii [Dostoevsky and Modernity: Materials of the VIII International Readings in Staraya Russa]. Novgorod, 1994. Pp. 121-130. (In Russ.)

7. Leibov R. Zametki o "Skvernom anecdote" [Notes about the "A Nasty Story"]. Novoe literaturnoe obozrenie [New Literary Bulletin]. 1994. № 8. Pp. 158-173. (In Russ.) 